\title{
SMEs DIGITALIZATION AND THE SHARING ECONOMY
}

\section{Milanka Bogavac}

Faculty of Business and Law of the "Union - Nikola Tesla" University, Belgrade, Serbia

\section{Lyudmila Prigoda}

Maikop State Technological University, Faculty of Finance and Economics, Maykop, Russia

\section{Zoran Cekerevac}

Faculty of Business and Law of the "Union - Nikola Tesla" University, Belgrade, Serbia

\section{OMESTE}

JEL Category: D83, L15, L86

\begin{abstract}
The paper analyzes the digitalization and sharing economy influences on the doing business and opportunities of small and medium-sized enterprises. Particular consideration was given to the digital transformation of SMEs in the modern world and to the various aspects of SME strategies in relation to digitalization, identifying four core enterprise groups: Digital Business Defender, Digital Business Prospector, Digital Business Analyzer and Digital Business Reactor. Digitalization was then analyzed as a contemporary worldwide process of improving performance and competitiveness, and its advantages and disadvantages were pointed out. After that, the new digital economy, the sharing economy, is analyzed. The benefits of this approach to resources are particularly emphasized, but also the risks it entails, especially regarding job security. As inevitable, the application of modern information and communication technologies is emerging in the digital economy. The research supports the authors' conclusion that not everything is in technology, but that anything cannot be done without it. The authors also concluded that SME digitalization is influenced by both internal and external factors and that the main internal factor is the owner/manager's attitude towards modern technologies and their willingness to incorporate the technology into the business of their enterprise. A state has emerged as an external factor, which can influence the digitalization of SMEs through various incentive measures. This work can be of use to anyone who is interested in analyzing the business of SMEs in contemporary conditions, as well as to SME managers/owners.
\end{abstract}

Address of the corresponding author:

Keywords: SME, digitalization, sharing, Milanka Bogavac

㪯”bogavac.milanka@gmail.com 


\section{DIGITAL TRANSFORMATION}

When talking about digital transformation, it is thought primarily of the process of infiltrating digital strategies and technology in the company. This can subtitle everything, from introducing new devices that would allow employees to work remotely, through creating mobile apps to improve internal communications or work without paper, up to adoption digital data collection solutions. In order to remain competitive, business societies must not ignore the widespread digital revolution. Therefore, companies of all sizes continuously explore the digital transformation and how to properly use available technologies to become more efficient and reduce costs. Many small and medium-sized enterprises (SMEs) have been looking for a long time to find technology that will allow them to work without paper. According to Xerox, in $2017,81 \%$ of the SMEs wished to eliminate paper from their business in the following 12 months (Lobel, 2017). Until the mid of 2019, there were no studies on the realization of this idea, but in any newspaper title, and in any available study, it did not appear any information that any SME eliminated the use of paper from business. It is a too complex and difficult task.

Within this research, under the term "digitalization", it will be considered the integration of digital technologies in all the pores of doing business of SMEs.

Digitalization offers new opportunities for SMEs, including the possibilities of global trade, innovation, and growth. With relatively low costs, SMEs can access knowledge networks and strengthen their competitiveness in the innovation of products and services and improve production processes. This should also be added to a wide range of opportunities that provide big data and their analysis. They help the SME better understand internal processes, customer and partners' needs, and the overall business environment they are in. Digitalization facilitates SMEs' access to skills and talents, as it makes to them available outsourcing and online renting of

1 Lean startup is the methodology of development of business society and/or product, which aims to reduce the product development cycle and quickly detect whether the proposed business model is sustainable; services as well as links with experienced partners (OECD, Key Issues for Digital Transformation in the G20, Report prepared for a joint G20 German Presidency/OECD conference, 2017). Mobile Banking and online payments also have a positive and important impact on SMEs. All this allows young SMEs to start out as a lean startup ${ }^{1}$, with small investments and low initial costs.

However, it is not as convenient for SMEs as it might look. Even now, many SMEs are not able to take advantage of digitalization due to restrictions on the adoption of digital technologies. In most countries, differences in accepting digitalization between large companies are small because they are present on the Internet and interconnected. With the decrease in the size of economic societies, differences are becoming larger. The gap is growing when one analyzes participation in electronic trade and the implementation of sophisticated applications. In OECD countries, software applications for business Resource Planning (ERP) for management of business information flows are popular in large companies (78\% in 2016), but not in SMEs $(<28 \%)$. In many countries, there is also a huge gap in the cloud of computing. (OECD, 2018) This is illustrated in figure 1.

The analysis conducted within the OECD project Going Digital shows that the SMEs' lag in adopting digital technologies is based on a lack of investment in appropriate knowledge-based assets. This includes investing in human resources, research and development, innovation, and organizational changes. Furthermore, SMEs are facing many challenges in terms of digital security and privacy, primarily due to the lack of capacity for evaluation and risk management. (OECD, Going Digital: Making the Transformation Work for Growth and Well-Being, 2017) In overcoming the observed challenges, politics can help a lot. The basic prerequisite is a provision of quality connections and networks, but targeted policies may help the SMEs to accept and implement the digitalization of business more quickly.

This is achieved by adopting a combination of experiments, iterative product launch, and validated learning. Under the term validated learning, it is considered the process of discovering valuable facts. 


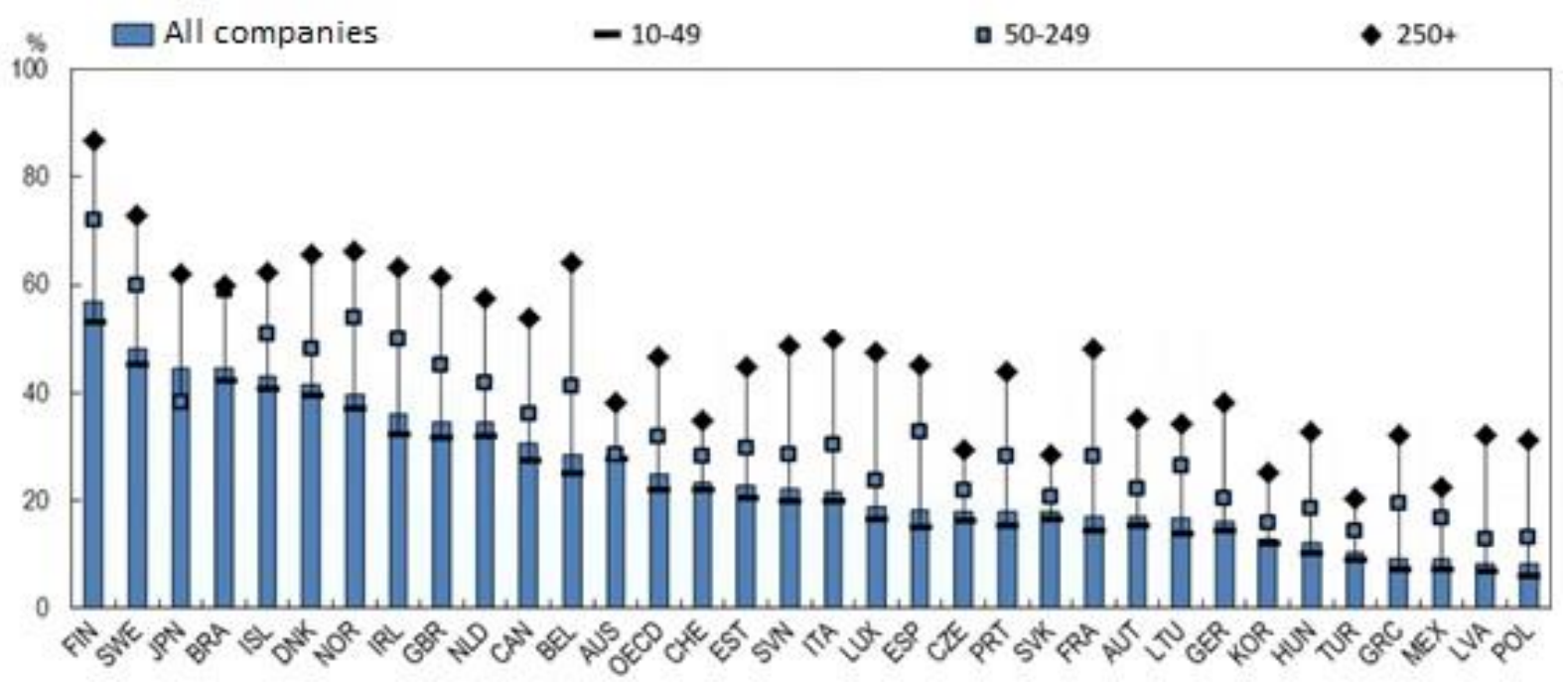

Figure 1 SMEs lag in the adoption of sophisticated digital technologies

Source: Authors' processing (OECD, Strengthening SMEs and entrepreneurship for productivity and inclusive growth - Key issues paper, 2018)

In terms of digitalization, the most important is the strategy of the SME itself. In relation to the strategy for the implementation of ICT, the digitalization of the company could be grouped into four groups (Miles \& Snow, 2003) (Viscusi, 2015):

- Digital Business Defender (DBD, defender) is an organization that focuses on competitiveness in a narrow and well-defined (product-service)-market in digital business, mainly giving attention to efficiency and productivity, and improvement of existing operations.

- The digital Business Prospector (DBP) is an organization that focuses on the continuous differentiation and innovability of products and/or services and continuously seeks new opportunities of the digital market, primarily by giving attention to experimentation. These companies usually have a decentralized management structure.

- Digital Business Analyzer (DBA) is an organization that operates on two markets, on one stable and with a limited degree of digitalization, and in the second highly digitalized, developed and susceptible to frequent changes. In the first market, the organization functions as a defender, while on the other acts as a prospector. Because of their orientation, such business companies have a matrix organizational structure that on the one hand is oriented to budgetary financing of its stable activity, and on the other hand, their business is based on individual projects, i.e. on the development groups that are forming and financed by the current projects. ${ }^{2}$

- Digital Business Reactor (DBR) is an organization that is unable to respond efficiently to changes and uncertainty in the business environment, due to inadequately articulated strategy or organizational structure which is in an improper manner related to the strategy or still follows outdated strategies and structures.

Digitalization is, above all, sociological change, not technical. This can be seen from the fact that everything about it mostly contains "why?": Why do users use social networks? Why are they using mobile devices? Why does big data show trends? Why can companies buy and use consumer products? Why is it easier to manage systems in the cloud? (Baxter-Reynolds, 2014)

2 The person which use metal detector while searching for metal (gold) objects in the ground. 
2 DIGITIZATION AS A MODERN PROCESS OF PERFORMANCE IMPROVEMENT

The wave of digitalization developed at the end of the Second Decade of the twenty-first century, some call the third or fourth industrial revolution or "Second Machine Age" (Brynjolfsson \& McAfee, 2011) (Valenduc \& Vendramin, 2017). To emphasize the effect of digitalization Autio (2017) called it a digital disruption. The simplest example of one such digital disruption could be the appearance of the Uber. It was a digital disruption that disturbed taxi companies. Those days practice was a phone call to a taxi carrier's central office and booking a taxi through the operator, or, simply, stopping the taxi by waving a hand. Uber has enabled users to know the price of the drive before entering the vehicle. The payment is done at the end of ride on the pre-selected way, which can be: credit card payment, Google pay, Apple pay, cash, or, only in India, using "Airtel Mobile wallet" (MDT, 2012) or "Unified Payments Interface (UPI)" (Swarajya Staff, 2017). What the cab drivers' answer could be? The protests and trials were one of the possibilities. The other, creating alternative applications and adapting to new conditions. And both the answers came up. In some countries, taxi drivers organized protests and pressured on authorities to ban this service, and/or a lot of trials were initiated. In some other, taxi business companies adapted and let into the use of their own applications to better communicate with users. The second alternative is considerably more favorable for the users of taxi services and will certainly win despite administrative obstacles.

A similar digital disruption occurred when Netflix appeared. For a relatively small amount of money, subscribers may select the video content that interests them. Instead of getting movies from TV companies and cable operators and watching them on their TV with plenty of commercials, the user can get them on their computer and then reroute them to the TV where they can watch them without advertisements. This disruption greatly affects the monopoly status and the income of the TV companies, because with reducing the number of users the importance of advertising is also reduced together with the prices per individual advertisement. This is multiple negative for the operations of TV companies. The only real response to this disruption may be to adapt the radio-diffusion companies with a new situation and offering content in a new way that would include also a video on demand and web delivery of content, and new benefits for subscribers.

Digitalization has already made significant changes in relation to the engagement of the workforce and the necessary knowledge and skills that workers should possess in employment and during employment engagement. Automation introduced robots and even "artificial intelligence" into production processes which provided a more balanced production, and higher quality of products and production with higher series and increased productivity, safety, and other positive indicators. But, in parallel with these positive effects, the gap between employment and productivity appeared. The number of jobs is decreasing, and productivity is growing (Brynjolfsson \& McAfee, 2011, p. 188).

In the industry, the issues of employment and the workers ' status are more clearly defined, but digitalization also here achieves a significant impact. According to the IndustriAll (2015) "digitalization is massively affecting employment and has specific effects" that are reflected in:

- Endangering the number of jobs intended for people. It is estimated that around $40 \%$ of jobs in the entire economy will be replaced with digital technologies.

- The concentration of power and wealth in digital electronic business platforms. This jeopardizes other participants in the chain of values, as they reduce the opportunities for investing and ensuring favorable working conditions and salaries to their employees.

Jeopardizing basic employment settings. Fulltime continuous employment can become rare because many tasks can be performed from a remote location or automated. Competition is created at the world level in work prices and the quality of employees.

- Creating conditions for asymmetric, vertical and unilateral control of workers, but also for horizontal, multilateral cooperation among workers. Which form will prevail will depend on political will, not on technology.

- One of the important features of digitalization is "transparency". Analysis of this trend requires a lot of time and carries with it many 
issues that within this study will not be thoroughly reviewed, but it is visible emergence of "digital discrimination" in certain areas. Digital discrimination itself is not explored enough yet, but as an example, it can serve a study published by Edelman and Luca (2014). The study is related to Airbnb and demonstrated that when "a new data set combining pictures of all New York City landlords on Airbnb with their rental prices and information about characteristics and quality of their properties" was used, "non-black hosts are able to charge approximately $12 \%$ more than black hosts, holding the location, rental characteristics, and quality constant ... These results highlight the risk of discrimination in online marketplaces, suggesting an important unintended consequence of a seeminglyroutine mechanism for building trust." (Edelman \& Luca, 2014). A similar analysis was done by Pope and Sydnor (2008) for the new market P2P lending. Their analysis showed that those who placed the black man picture will have $25-35 \%$ less chance of getting a loan than those who placed a picture of the white man, although they have a similar credit profile. The deeper analysis of Pope and Sydnor concluded that P2P the market of lending is treating the race more equal than expected and reducing the chances of obtaining loans are more influenced by other factors, but the fact that the odds are less it stays.

Digitalization also brings new challenges. Although it is already in full swing, many unanswered questions are still attached to it. There are still unclear relationships between workers and employers, men and platforms. Also, questions about monopoly and competition, future development, whether or where and how to pay taxes need answers. Digitalization and globalization have resulted in issues of global significance. Given the nature of digital goods and services, it is already noticeable that it is difficult to monitor the real influence of digitalization on changes in the economy and society.

\section{NEW DIGITAL ECONOMY - SHARING ECONOMY}

By analyzing digitalization, a new phenomenon can be observed, the so-called "sharing economy". Under the sharing, it is commonly implied "a form of social exchange, which takes place among people who know each other and that goes without any profit" (Eckhardt \& Bardhi, 2015). However, when sharing is market-oriented, it is difficult to align it with the previous sharing definition. This is about an economic exchange in which participants expect some benefit.

In the economy of sharing, it is understood that companies and users have less desire to possess something, and more often what they have or what they need, they share with others, whether it is real estate, business premises, production resources or other material goods. This is a brand-new business model brought by the Internet and digitalization. As examples can serve timesharing, bicycle-sharing, Airbnb, Uber, Car:Go, Taxify (Bolt), etc. However, as part of the sharing economy, issues related to the working force appear. The economy of sharing includes also independent performers, temporary workers, selfemployed, half-time workers, free workers, and ' free agents ', so it is to expect in the United States by 2020 , over $40 \%$ working forces to have uncertain employment. Up to 2025 most working forces will have uncertain employment. (Reich, 2015). The decline of demand or sudden change of consumer needs, or injury or disease, can make impossible to pay the bills. "It eliminates labor protections such as the minimum wage, worker safety, family and medical leave, and overtime." (Reich, 2015)

In the narrowest sense, sharing can be considered as a "peer to peer" (P2P) model of communication and doing business, but in the case of appearance of platforms as a mediator in communication and realization of sharing, especially in cases that include payment of goods/services, it may be classified in $\mathrm{B} 2 \mathrm{C}$ or $\mathrm{C} 2 \mathrm{~B}$ (or, more precisely in B2B2C or C2B2B) business models, depending on what stage is the sharing process at.

The economy of sharing is a very broad area, and for ease of parsing, Edgar Szoc (2015) has proposed three criteria:

- A criterion of the monetization of goods and services offered,

- A criterion of investment, i.e. the needs of investments in physical capital, and Location criterion, i.e. the possibility of relocation of the service. 
The first criterion can distinguish cases such as Wikipedia or "Couchsurfing" where the sharing of information or the couch is completely free (although Wikipedia lives from user donations) and platforms such as Uber, eBay, or Airbnb that charge their services to service providers. In both cases, the types of services that are provided are very similar. This criterion allows segregating the actual collaborative economies in which the objective of the participant is not to achieve profits. However, it is needed, but it is not enough, because free services are provided also by Google, Facebook, and Twitter, but their owners expect dividends.

The second criterion provides a distinction according to whether capital is required to provide the service, as in the case of Uber or Airbnb, or it is only enough to offer own workforce as in TaskRabbit or "Rent a Friend" cases. Even in the second case, when the services of their own workforce are offered, it is not necessary to deal with poorly paid jobs. Platforms that are specialized for providing services of highly educated experts also appear here.

The third criterion enables differentiation between services that are related to a specific geo-location (the location of the apartment, cars, ships) and services that can be made through the Internet and independently from the purchaser and the perpetrator locations (accounting operations, Intellectual services...). It specifies the possibility of creating an alternative, parallel labor market, which with the application of appropriate platforms enables long-distance employment and gives many advantages to employers and major competition for potential employees, especially in highly developed countries. As an example, it can serve the website upwork.com with its motto: "Hire freelancers. Make things happen." (Upwork, n.d.) This website does not see itself as an employer, but an "online workplace for the World", a platform for top business companies for engagement and work with the world's most talented independent experts (Degryse, 2016). Competition is global and differences between the countries where the service bidders live disappear. Practically, one can talk about virtual migrations of highly skilled workers. There is a similar situation with the Amazon Mechanical Turk (MTurk) platform that works in the labor market that requires human intelligence. The MTurk Web service allows companies to access this market and engage diverse "on request" labor force. Developers can use this service to incorporate human intelligence directly into their applications. The Amazon called this model "Artificial artificial intelligence". Basically, it's about outsourcing. The idea is that some tasks instead of computers are performed by ordinary users, and the Amazon as a platform takes its percentage. (Amazon, 2018)

Although digitalization has brought new employment opportunities, it should be necessary to keep in mind that such employment is not regulated by any form of contract that would protect the rights of workers. The worker is left to fend for himself in the market. This way of hiring, although in every way problematic from the legal aspect is spreading at high velocity and will have a growing impact on the labor market throughout the world.

In connection with the general digitalization and appearance of the mass collection and storage of all the data, known as "Big Data", there appeared a need for a summarizing of that data by the extraction of small amounts of precious, condensed, data. Although it is generally widely thought that these procedures are fully automated, it is far from the truth and most experts for processing large amounts of data deal with tasks of the acceptable data interpretation. They work in groups, and their tasks are divided into very small and simple continuously repeatable tasks. This would suit modern, digital, Taylorism. Further sharing of jobs on new subgroups and even smaller jobs can lead to further reductions in the employment needs of skilled personnel, which will bring workers to a more disadvantaged position.

In the aforementioned "Mechanical Turk" (Mturk) a multitude of workers work on jobs that are not yet possible to automate, but under conditions that are very unfavorable for workers. "As contractors, AMT workers are excluded from the protections of minimum-wage laws. Amazon also allows employers to decide whether or not they want to pay. The intention is to let employers set standards. The effect is that unscrupulous AMT users steal wages. (Irani, 2015). " To protect the 'Turkers' Irani and Silberman, they started the website turkopticon.ucsd.edu with the possibility to download an Internet browser add-on that could obtain information about the prior experience of 
Turkers who worked for the employer who offers the job on AMT. This site has served as an inspiration for the initiation of other forms of protection, such as in Germany, through the Green Book (Nahles, 2015), and then through the White Book (Nahles, 2017)

The examples of sharing economy are more detailed explained in (Martucci, 2018), but some examples of the sharing economy will be reviewed here with comments and explanations of the authors:

- P2P borrowing; P2P Loans existed before the computer appeared, but by the appearance of Internet communication, they got a new form. In recent days, platforms have emerged that individuals can borrow each other's money without common banking procedures. The platform in these cases determines the interest on the basis of the credit history of borrows. This way of borrowing is risky for the one who gives the money but is becoming more popular because of the more liberal standards for approving loans. Application of blockchain technology and the appearance of many of the startups in this area can affect the severity of the whole process. It is undoubtedly that the expansion of this way of borrowing will affect the banks to reconsider their credit approval policy.

- Group financing; Similarly, as P2P borrowing, group financing links those who need money with those who have it and want to invest it. On platforms such as Kickstarter or Indiegogo entrepreneurs, artists and others can present their ideas and projects to potential financiers, to define their financial needs and the deadline they plan to collect the money they need. In this way, entrepreneurs and other SMEs can dramatically reduce costs and obtain an outstanding tool for fundraising. Some of the platforms keep the money until the deadline is set, and then submit it to the borrow recipient if the campaign is successfully completed or return to lenders if the campaign was unsuccessful. The campaign is successful if the whole defined amount is collected (or more) by the set period. Like in P2P borrowing, there is a possibility that the borrow recipient has no intention of returning the loan. As an alternative to lending, there is a grant. In this case, the money is collected in the same way, but the loan-recipient is not expected to return the "loan". In order to encourage lenders to fund grants, borrow recipients sometimes offer something in return, but very often the lenders meet only emotional pleasure that they participated in a useful project.

- Renting of apartments and houses and couch surfing; Platforms such as Airbnb, VRBO, and Couchsurfing connect property owners with people who need lodging during the trip. Owners of apartments and houses when they are not in their facilities are given the possibility to offer them, at the prices they specify, to others to use by informing them of available dates. Travelers choose what is best suited to their needs based on the offer. Before handing over the property to use, the user and the owner can sign a contract on the terms of use of the object, and usually, the user leaves a deposit as a measure of protection of the owner in case of property damage. It is also possible for the user to evaluate the owner and the object, and that the owner of the object evaluates the user upon the expiration of the rent. This can be useful for later renting on the same platform. One of the risks for this type of business can be interference by a state under pressure from the hotel industry and fear that it will not collect taxes from such services.

- Ridesharing and car-sharing; If one can say that the state doesn't look favorably on renting apartments and houses, car-sharing and the ride-sharing situation can be even worse, primarily due to the impact of taxis associations. Car- and ridesharing are about the need of a user to use the car in situations where their personal car is not available, or when they do not want to use it, or when they do not possess it at all. For such situations, taxi services can be used, but given the prices of taxi services and the current needs and capabilities of the taxi service users, it does not have to be an acceptable solution. In ridesharing, using the Uber or Lyft applications, the user can mark its position and target travel point, and one of the closest drivers with its private vehicle will satisfy user needs. Using the applications Car2Go and/or Zipcar user can locate the nearest free vehicle, provided by a profit or non-profit 
organization, take the vehicle, drive it by itself to the target point and leave it in some parking lot, not thinking about it further, and user pays only for the time spent in the vehicle. With the GetAround application, the user can rent one or more of the vehicles of private persons and pay the use of vehicles per hour or day, with the condition that the vehicle will return to the owner in the agreed term. Car-sharing is like the services provided by the classic car rental company, except renting is done in a much more flexible way. The model is applicable also when SME or a large company is the owner of vehicles, but to participate the SMEs need the support of the state and the creation of proper legislative regulation.

- Coworking; Coworking existed before the computer, but the appearance of IT-enabled that in one place, in the same space, freelancers and entrepreneurs work in a comfortable environment along with other professionals. Many cities and universities have created such environments where they have provided fully equipped workplaces for more users, and users pay rent on a weekly or monthly basis depending on how much space they use and how much time they spend. In addition to the advantages of this kind of work, entrepreneurs and freelancers get the ability to communicate with similar ones working in other areas, which provides them better inclusion in society and the economy.

- Special purpose services; Internet platforms enable SMEs to offer special, specific, services intended for a particular group of users. For example, the Spinlister platform enables bicycle rental; the DogVacay platform allows dog owners to find dog-lovers who will hold their pets while they are absent for travel. In this way, a dog lover who protects someone's pet will have the opportunity to earn something. In similar ways, SMEs can create their own platforms to participate in many sharing activities including wardrobe, sports equipment, and many other different things.

From the above, the benefits of sharing economy can be crystallized as:

- Cheaper goods and services,

- Supplementary income for service providers,

- New opportunities,
- Better socialization and connectivity.

On the other hand, identified risks are:

- The potential loss of privacy,

- Lack of warranty, or lack of enough warranties,

- Loss of control over ownership due to cooperation with others,

- Market disorders.

If the risks are considered more detailed, it can be seen that due to the increase of the short-term renting of flats (due to potential higher earnings) the rental market in the long term remains deprived of a large number of housing units, making it difficult to find an appropriate apartment. At the same time, it affects rent prices. An entrepreneur who works in a common space with others can count on getting the new useful information, but also that the part of its own information will be given to others, which would not be the case if he had his own space.

For now, it is possible to say that the sharing economy has perspective and that it is still in the experimental phase.

\section{IS EVERYTHING TECHNOLOGY?}

IN

At the time of the latest industrial revolution, anyone with a "smart" mobile phone can create an application or offer services and thus contribute to own budget. If it can do individuals, then also the SMEs can do the same. Therefore, a justified question appeared: Is everything in technology?

While the adoption of ICT and digital technologies is accelerating, the facts say that there is still a significant "digital divide" between small and large companies. (EC, 2011) To raise the level of adoption of digital technologies in SMEs, it is necessary to identify the challenges for their adoption in order to choose the paths of digitalization in accordance with the actual needs. Most SMEs cannot afford to employ digital experts and therefore the e-business and digital strategies of SMEs mainly depend on interest, understanding and digital skills of entrepreneurs and owners/managers. (Hynes, 2016, p. 3)

The challenges of adopting digital technologies in SMEs resonate with internal and external influences, and it is important to identify whether the owners/managers and/or staff have 
appropriate knowledge and interests or are lacking digital skills. In connection with the application of digital technology, often occurs a lack of interoperability between different ICT systems used for data exchange, distribution and exchange of information, and marketing. These systems are predominantly developed for big companies, and the discrepancy of such systems with the needs of SMEs may become the reason for the repulsion by the owners/managers. In addition, SMEs owners and managers are generally aware that investing in the latest digital technologies does not automatically mean better results of the business. To achieve this, they need to understand what these technologies can do and for what purpose they are designed. (Hynes, 2016)

Practically all innovations, immediately after the idea is shaped, move into the field of dependency of technology. Whatever is invented, is realized by the application of technologies or disappears as non-competitive. E. g, traffic in the cities is very often in the congestion zone. The idea was to replace the ownership of the vehicle with the possibility of using joint vehicles as needed by renting "an hour". In this way, according to the OECD report (2017), nine out of ten vehicles appear as unnecessary (Berge, 2018). However, the realization of the idea, immediately in the first step requires the use of digital technologies to answer the question of the nearest free vehicle. The next, about the right of the user to use the free vehicle, the payment of service and similar, it is necessary to apply ICT.

So, if one needs to answer the question, "Is everything in technology?" it could be said that it's not all about technology, but without the technology, it is hard to survive.

\section{CONCLUSIONS}

Digitalization has caused a digital disruption in society and major changes in all aspects of the business. Different societies reacted differently from complete (unjustified) negation to very quick adoption.

\section{WORKS CITED}

Amazon. (2018, 10 21). Product Details. Retrieved from Amazon Mechanical Turk (MTurk): https://www.mturk.com/product-details

There is a big difference in access to digitalization in SMEs and large companies. While large companies are massively using software applications to manage business process flows, this is not the case with SMEs. There is also a big gap in cloud computing. SMEs are lagging in adopting digital technologies due to a lack of investment in knowledge-based assets. In addition, SMEs are more exposed to the challenges in digital security and privacy.

The impact of digitalization is best reflected in the structure of created new jobs and in the structure of disappeared jobs and companies.

As a result of digitalization, a new phenomenon has emerged, a sharing economy that implies that businesses and users increasingly express the desire to satisfy their resource needs by sharing them with others. In this way, resources are used more rationally. This has transposed also to the workforce and to the tendency that employers increasingly employ workers for some period or part-time. This undoubtedly affects job security.

The benefits of the sharing economy are cheaper goods and services, additional revenue for service providers, new opportunities, and better socialization and connectivity. On the other hand, identified risks are the potential loss of privacy, the absence of job guarantees, or the lack of enough job guarantees, the loss of control over ownership due to co-operation with others, and market disruptions.

It can be said with certainty that the challenges of adopting digital technologies correlate with internal and external influences. As the main internal influence, it appears the interest of the managers/owners for new technologies and their ability to accept and use these new technologies, i.e., their possession of knowledge and skills in the field of IT application. The main external influence is the influence of a state. The state by various stimulus measures can support the process of digitalization in SMEs.

Finally, it is inevitable that most SMEs will have to either digitalize or disappear. 
Autio, E. (2017). Digitalisation, Ecosystems, Entrepreneurship and Policy. Perspectives into Topical Issues Is Society and Ways to Support Political Decision Making. Government's Analysis, Research and Assessment Activities Policy Brief(20).

Baxter-Reynolds, M. (2014, 04 23). Everyone is 'going digital,' but just what does that mean? Retrieved from ZDNet: https://www.zdnet.com/article/everyone-is-going-digital-but-just-what-does-thatmean/

Berge, Ø. (2018, 01 23). Shared, intelligent mobility will transform urban life. Retrieved from COWI: https://www.cowi.com/insights/green-shared-and-intelligent-mobility-will-change-our-lives

Brynjolfsson, E., \& McAfee, A. (2011). Race against the machine: how the digital revolution is accelerating innovation, driving productivity, and irreversibly transforming employment and the economy. Lexington: Digital Frontier Press.

Brynjolfsson, E., \& McAfee, A. (2011). Race Against The Machine: How the Digital Revolution is Accelerating Innovation, Driving Productivity, and Irreversibly Transforming Employment and the Economy. Lexington, Massachusetts: Digital Frontier Press.

Degryse, C. (2016). Digitalizacija ekonomije i njezin utjecaj na tržišta rada. Brussels: ETUI aisbl.

EC. (2011). Stimulating innovation through smart use of ICT: assisting SMEs to participate in digital value networks in the tourism and food industry, in the Single Market. Brussels: European Commission.

Eckhardt, G., \& Bardhi, F. (2015, 01 28). The sharing economy isn't about sharing at all. Harvard Business Review. Retrieved from https://hbr.org/2015/01/the-sharing-economy-isnt-aboutsharing-at-all

Edelman, B., \& Luca, M. (2014). Digital discrimination: the case of Airbnb.com. Harvard Business School. Retrieved from https://www.hbs.edu/faculty/Publication\%20Files/Airbnb_92dd60866e46-4eaf-9cea-60fe5ba3c596.pdf

Hynes, B. (2016). Going Digital in the Small Firm - Is it all about technology!!! DIGA - Digital Innovations for Growth Academy.

industriAll. (2015, 12 3). Digitalisation for equality, participation, and cooperation in industry - More and better industrial jobs in the digital age. Retrieved from industriAll Europe Trade Union: http://www.industriall-europe.eu/database/uload/pdf/2015929PositionPaper_2015XX_DigitalisationOfIndustry_DRAFT-v1.pdf

Irani, L. (2015). Justice for 'data janitors'. Public Books. Retrieved from https://www.publicbooks.org/justice-for-data-janitors/

Lobel, B. (2017, 02 28). What is digital transformation and what does it mean for SMEs? Retrieved from http://smallbusiness.co.uk: http://smallbusiness.co.uk/digital-transformation-mean-smes2537128/

Martucci, B. (2018, 10 02). What Is the Sharing Economy - Example Companies, Definition, Pros \& Cons. Retrieved from Money Crashers: https://www.moneycrashers.com/sharing-economy/

MDT, M. D. (2012, 03 29). Airtel's mobile wallet service. Retrieved from Moneylife: https://www.moneylife.in/article/airtels-mobile-wallet-service/24606.html

Miles, R., \& Snow, C. (2003). Organizational Strategy, Structure, and Process - Stanford business classics. Stanford, California: Stanford University Press.

Nahles, A. (2015). Gruen Buch. Berlin: Bundesministerium fuer Arbeit und Soziales. Retrieved from https://www.bmas.de/SharedDocs/Downloads/DE/PDF-Publikationen-DinA4/gruenbucharbeiten-vier-null.pdf?__blob=publicationFile 
Nahles, A. (2017). Weiss Buch Arbeiten 4.0. Berlin: Bundesministerium fuer Arbeit und Soziales. Retrieved from https://www.bmas.de/SharedDocs/Downloads/DE/PDF-Publikationen/a883weissbuch.pdf?_blob=publicationFile

OECD. (2017). Going Digital: Making the Transformation Work for Growth and Well-Being. Meeting of the OECD Council at Ministerial Level (pp. 3-30). Paris: OECD. Retrieved from https://www.oecd.org/mcm/documents/C-MIN-2017-4\%20EN.pdf

OECD. (2017). Key Issues for Digital Transformation in the G20, Report prepared for a joint G20 German Presidency/OECD conference. Berlin: OECD. Retrieved from https://www.oecd.org/g20/keyissues-for-digital-transformation-in-the-g20.pdf

OECD. (2017). Letter of Intent on the testing and large scale demonstrations of Connected and Automated Driving (CAD). Rome: OECD.

OECD. (2018). Strengthening SMEs and entrepreneurship for productivity and inclusive growth - Key issues paper. 2018 SME Ministerial Conference (pp. 6-24). Mexico City: OECD. Retrieved from https://www.oecd.org/cfe/smes/ministerial/documents/2018-SME-Ministerial-Conference-KeyIssues.pdf

Pope, D., \& Sydnor, J. (2008). What's in a picture? Evidence of discrimination from Prosper.com. Journal of Human Resources, 46(1), 53-92.

Reich, R. (2015, 11 30). Why The Sharing Economy Is Harming Workers - And What Can Be Done. Retrieved from Social Europe.

Swarajya Staff. (2017, 07 20). Now You Can Pay For Your Uber Ride Using UPI. Retrieved from Swarajya: https://swarajyamag.com/insta/now-you-can-pay-for-your-uber-ride-using-upi

Szoc, E. (2015, 04). Du partage à l'enchère : les infortunes de la "Sharing Economy ». Retrieved from Association Culturelle Joseph Jacquemotte: http://acjj.be/ancien/IMG/pdf/150413SEOnDemand2_1_.pdf

Upwork. (n.d.). Upwork. Retrieved 08 01, 2019, from Upwork: https://www.upwork.com/

Valenduc, G., \& Vendramin, P. (2017). Digitalisation, between disruption and evolution. Transfer, 23, $121-34$

Viscusi, G. (2015). Digital business innovation: roadmaps and attitudes from a FutureEnterprise perspective. Genie Logicie/(115), 36-41. Retrieved from https://infoscience.epfl.ch/record/214945/files/viscusi-genie.pdf

Received for publication: $\quad 24.10 .2019$

Revision received:

17.12.2019

Accepted for publication: $\quad 10.01 .2020$

\section{How to cite this article?}

Style - APA Sixth Edition:

Bogavac, M., Prigoda, L., \& Cekerevac, Z. (2020, January 15). SMEs digitalization and the sharing economy. (Z. Cekerevac, Ed.) MEST Journal, 8(1), 36-47. doi:10.12709/mest.08.08.01.05

Style - Chicago Sixteenth Edition:

Bogavac, Milanka, Lyudmila Prigoda, and Zoran Cekerevac. 2020. "SMEs digitalization and the sharing economy." Edited by Zoran Cekerevac. MEST Journal (MESTE) 8 (1): 36-47. doi:10.12709/mest.08.08.01.05. 
Style - GOST Name Sort:

Bogavac Milanka, Prigoda Lyudmila and Cekerevac Zoran SMEs digitalization and the sharing economy [Journal] // MEST Journal / ed. Cekerevac Zoran. - Belgrade - Toronto : MESTE, January 15, 2020. - 1 : Vol. 8. - pp. 36-47.

Style - Harvard Anglia:

Bogavac, M., Prigoda, L. \& Cekerevac, Z., 2020. SMEs digitalization and the sharing economy. MEST Journal, 15 January, 8(1), pp. 36-47.

Style - ISO 690 Numerical Reference:

SMEs digitalization and the sharing economy. Bogavac, Milanka, Prigoda, Lyudmila and Cekerevac, Zoran. [ed.] Zoran Cekerevac. 1, Belgrade - Toronto : MESTE, January 15, 2020, MEST Journal, Vol. 8, pp. 36-47. 